\title{
Genetic and environmental analysis of diseases with major economic impact in Israeli Holsteins
}

\author{
Joel Ira Weller, ${ }^{1 *}$ Ephraim Ezra, ${ }^{2}$ and Michael van Straten ${ }^{3}$ \\ ${ }^{1}$ Institute of Animal Sciences, Agricultural Research Organization, The Volcani Center, Rishon LeZion 7505101, Israel \\ ${ }^{2}$ Israeli Cattle Breeders Association, Caesarea Industrial Park 3088900, Israel \\ ${ }^{3}$ Hahaklait Veterinary Services, Caesarea Industrial Park 3088900, Israel
}

\section{ABSTRACT}

Incidences of ketosis, metritis, mastitis, and retained placenta were studied in Israeli Holstein cows calving between 2008 and 2017. These diseases were selected based on their economic impact. Ketosis, metritis, and retained placenta were scored dichotomously. Mastitis was scored as absent, a single occurrence during the lactation, or more than 1 occurrence. Ketosis and metritis were recorded during the first $21 \mathrm{~d}$ after calving, retained placenta during the first $5 \mathrm{~d}$ after calving, and mastitis up to $305 \mathrm{~d}$ in milk. The effects of herd-yearseason, calving age, month of calving, gestation length, and occurrence of dystocia were included in the firstparity analysis models. All effects were significant for metritis and retained placenta. For ketosis, all effects were significant, except for gestation length. For mastitis, only the effects of herd-year-season and calving age were significant. Variance components were computed by the multitrait animal model. The 4 diseases were analyzed jointly based on first-parity records, and each disease was analyzed separately for parities 1 to 3 with the different parities considered separate traits. The 4 disease traits in first parity were also analyzed jointly with the 6 major traits included in the Israeli breeding index: milk, fat, and protein production; somatic cell score; female fertility; and longevity. Heritability was highest for metritis and lowest for mastitis, but all heritabilities were $<0.07$, similar to previous studies. For all 4 diseases, genetic correlations among the first 3 parities were $>0.65$, and all residual correlations were $<0.07$. Selection of herd-years assumed to have more accurate recording of mastitis did not result in higher heritability estimates. Genetic correlations between the disease traits and milk, fat, and protein production were economically unfavorable, while correlations between the disease traits and somatic cell score, female

Received November 21, 2018.

Accepted July 18, 2019.

*Corresponding author: joel.weller@mail.huji.ac.il fertility, and longevity were economically favorable. Expected genetic changes in the disease traits after 10 yr of selection with the current Israeli breeding index were all $<1 \%$, except for ketosis, which was predicted to increase by $1.5 \%$. Inclusion of these traits in a proposed index with the disease traits constituting $7 \%$ of the index would result in only marginal improvements for the disease traits and adversely affect genetic gain for fat and protein production. Thus, inclusion of these traits in the breeding index cannot be justified economically. Key words: ketosis, metritis, mastitis, retained placenta

\section{INTRODUCTION}

Shook (1989) listed the criteria that a potential trait must meet to be included in the selection objective. First, the trait should have an economic value. Second, it must have sufficiently large genetic variation in relation to its economic value and heritability. Third, it should be measurable at a low cost and consistently recorded. The earlier a trait can be recorded, the more useful it is in selection. In addition, genetic correlations among economic traits must be considered. Breeding for 2 traits that have a strong negative genetic correlation will be inefficient (Weller, 1994). An indicator trait may be favored if it has a high genetic correlation with the economically important trait, is easier to record, has a higher heritability than the economic trait, or can be measured earlier in life (Miglior et al., 2017).

Diseases in dairy cattle are a major source of economic loss due to reduced production, death, involuntary culling of animals, veterinary treatments, lost milk due to antibiotic use, added labor, delayed conception, low milk quality, and increased susceptibility to other diseases. Average costs per case in primiparous cows were estimated to be $\$ 325$ for mastitis, $\$ 77$ for ketosis, $\$ 172$ for metritis, and $\$ 150$ for retained placenta (Liang et al., 2017). Costs are higher in later parities. In addition, concerns over antibiotic use and ethical and animal welfare matters have become major considerations 
(Miglior et al., 2017). Kelton et al. (1998) reviewed over 300 papers published from 1970 to 1996 . The median incidences (per cow and year) of calving diseases were $8.6 \%$ for retained placenta, $10.1 \%$ for metritis, and $4.8 \%$ for ketosis. More recently, Parker Gaddis et al. (2012) found mean frequencies of $8.0 \%$ for retained placenta, $12.3 \%$ for metritis, $5.1 \%$ for ketosis, and $18.0 \%$ for mastitis in an analysis of 19 studies. However, both studies reported large ranges in the incidences, based partly on the lack of consensus with respect to diagnosis and which parities were analyzed.

The distributions of most disease traits are discrete and generally binomial; that is, either the disease has or has not been recorded during a lactation. Therefore, several studies have proposed that genetic analysis of these traits should be based on either logistic or threshold models that correctly account for the discrete nature of the records (e.g., Heringstad et al., 2005; Parker Gaddis et al., 2014). The main disadvantage of these methods is that they generally can only be applied to sire models. Thus, not all relationships among animals are used to compute genetic evaluations, and genetic evaluations are not computed for females. Utilization of female records becomes even more important with genomic evaluation because a large fraction of females are now routinely genotyped (https://queries.uscdcb .com/Genotype/cur_density.html). Consequently, the USDA has decided to use a single-trait linear animal model for routine evaluation of disease traits (Parker Gaddis et al., 2017).

Heritabilities of direct measures of disease traits are mostly <0.1 (Pryce et al., 2016). Therefore, indicator traits with continuous distributions and higher heritabilities have been proposed. Mastitis is clearly the most economically significant disease affecting the dairy industry. Coffey et al. (1986) approximated genetic correlations between SCS and measures of infection to be between 0.36 and 0.67 . Weller et al. (1992) found that the genetic correlation between bacterial infection and SCS in Israeli Holsteins was near unity, but the genetic correlation between SCS and mastitis was only 0.3. Somatic cell score was included in US selection indices beginning in 1994 (Shook, 2006) and in the Israeli breeding index since 1996. Indicators for selection and the genetic evaluation of metabolic diseases, including ketosis and displaced abomasum, were considered by Pryce et al. (2016).

For milk production traits and the important nonproduction traits, including SCS and fertility, genetic correlations among parities are strong, although less than unity (Weller and Ezra, 2004). Thus, genetic evaluations based on first parity provide good indications of lifetime performance. With the exception of mastitis, very few estimates of genetic correlations among pari- ties exist for disease traits. Parker Gaddis et al. (2017) computed heritabilities for US Holsteins including parities 1 to 5 with a single-trait animal model for 6 disease traits including the cows' permanent environmental effect, which was $<0.1$ for all diseases. This model assumed equal heritabilities among parities and a genetic correlation of unity among parities.

The first objective of this study was to estimate heritabilities and genetic correlations among the 4 disease traits with the greatest economic impact in Israeli Holsteins: mastitis, ketosis, metritis, and retained placenta. A secondary objective was to compute the genetic and residual correlations among these traits and the major traits included in most current national breeding indices. Using these results, we predicted genetic trends for the disease traits based on the current Israeli breeding index (which includes 9 traits but is based chiefly on fat and protein production, SCS, female fertility, and longevity) and an alternative index including nonzero coefficients for the 4 disease traits. Finally, because mastitis is generally recorded by farmers, we investigated whether heritability and genetic correlations among parities and correlations between mastitis and SCS are affected by selection of herds assumed to have more accurate recording for this trait.

\section{MATERIALS AND METHODS}

\section{Definitions of the Diseases}

Traits were scored on milk-recorded Israeli-Holstein cows calving between 2008 and 2017. Almost all milk cows in Israel are Holsteins, and $>90 \%$ are milk-recorded. Valid first-parity records for ketosis were available for 278,228 cows, and records for similar numbers were available for the other traits. The number of first-parity cows with valid records for ketosis by calving year is given in Table 1. Ketosis, metritis, and retained placenta were scored dichotomously. Mastitis was scored as absent (0), a single occurrence during the lactation (1), or more than one occurrence (2). All cows underwent a clinical examination (including uterus) between 5 and $12 \mathrm{~d}$ postpartum. Ketosis and metritis were recorded during the first $21 \mathrm{~d}$ after calving, retained placenta during the first $5 \mathrm{~d}$ after calving, and mastitis up to 305 DIM. Ketosis was determined by Ketostix semiquantitative urine strips (Ketostix, Bayer, Leverkusen, Germany) using the $1.5 \mathrm{mmol} / \mathrm{L}$ threshold. Metritis was defined as abnormal vaginal discharge $<21 \mathrm{~d}$ after calving, as diagnosed by the attending veterinarian. Metritis was scored as positive, even if no systemic symptoms were observed. This definition is more inclusive than the definition used in most previous studies (Kelton et al., 1998; Pryce et. al, 2016). Retained 
placenta and mastitis were generally determined and recorded by the herd manager.

As noted previously, mastitis was usually farmer recorded, and records may not be reliable in many herds. To select herds with reliable recording, cows with valid records in parities 1 to 3 were first divided into herdyear groups. Of 5,931 herd-year cohorts, 4,076 had $\geq 50$ records. Of these, only 1,443 herd-years had a frequency of mastitis $>4 \%$. We assumed that recording for mastitis was more reliable in these herds, as opposed to herd-years with no or very few recorded occurrences of mastitis. We computed separate analyses for all records and for cows from the selected herd-years.

\section{Statistical Analysis}

First-parity incidence of each disease was analyzed by the General Linear Model procedure of SAS (SAS Institute Inc., 2011), using a fixed linear model. The models included the effects of herd-year-season of calving (HYS), calving age, month of calving, gestation length, and occurrence of dystocia. Two seasons were defined for each herd-year based on freshening date, from April through September and from October through March. Because both HYS and month of calving were fixed effects, some confounding was present between these 2 effects, and month of calving effects was only estimable within each 6 -mo season. Herd-yearseason was considered fixed in all the analyses because it was considered a "nuisance effect."

Variance components, heritabilities, and additive genetic and residual correlations were computed for all 4 disease traits by the multitrait individual animal model using the AIREMLF90 REML program (Misztal et al., 2014), which also computes standard errors for variance components and functions of components, including correlations and heritabilities. In addition to the additive genetic effect, each model included a fixed HYS effect as defined previously.

All cows with valid first-parity records for all 4 diseases were analyzed, with the diseases considered correlated traits. In addition, each disease trait was analyzed separately for parities 1 to 3 , with the 3 parities considered correlated traits. In this case a separate HYS effect was defined for each parity. All animals with valid first-parity records were included for each trait, even if later parity records were missing. Third-parity records were included if valid first- and second-parity records were available. Mastitis was analyzed for all data and including only the selected herd-years, as described previously. REML variance components were also computed for mastitis and SCS jointly, including all first-parity lactations with valid records for both traits. As was the case for the other disease traits, second and third parities were also included if valid records were available for the previous parities. The same procedure was applied for analysis of the selected herd-years.

Finally, the first-parity records for the 4 diseases and the main traits included in the Israeli breeding indexmilk, fat, and protein production; SCS; female fertility; and longevity - were analyzed jointly. Milk, fat, protein, SCS, and female fertility were scored as described previously (Weller and Ezra, 2004). All these traits were analyzed by the multitrait animal model, with each parity considered a separate trait. The analysis models included the effects of herd-year-season and parity. For these traits, one record is generated for parity, except for longevity, for which only a single record is calculated per cow. For culled cows, longevity was computed as the number of days from first calving to culling. For cows that had not yet been culled, expected longevity was computed as described by Settar and Weller (1999). For the disease traits, the model included a fixed HYS effect as described previously and all known relationships among animals with valid records. Three traits included in the current index were not included in the analysis: persistency, calving ease, and rate of stillbirth. Persistency was not included because it is only computed on complete lactations, and deletion of lactations that were terminated early would bias the results. The other 2 traits were not included because of low heritability and computing limitations. This analysis was computed by the MTC program (Misztal, 1994) because the number of records-by-trait exceeded the computing limitations of the available hardware. This program does not compute standard errors of the estimates.

In addition to all cows with records, all known parents and grandparents of cows with records and their sires were included in the analyses. Two unknown parent groups were included in the model for animals with unlisted parents, one for males and one for females.

Table 1. Number of cows included in the analysis for ketosis by freshening year ${ }^{1}$

\begin{tabular}{lc}
\hline Freshening year & Number of cows \\
\hline 2008 & 23,687 \\
2009 & 22,841 \\
2010 & 25,351 \\
2011 & 27,090 \\
2012 & 27,215 \\
2013 & 30,107 \\
2014 & 32,131 \\
2015 & 30,753 \\
2016 & 33,856 \\
2017 & 25,197 \\
Total & 278,228 \\
\hline
\end{tabular}

${ }^{1}$ Number of cows was very similar for the other disease traits. 
The number of cows with records and parents for each analysis is given in Table 2 .

The genetic and residual variance components from the analysis that included the 6 traits from the Israeli breeding index and the 4 disease traits were used to compute the vector of expected genetic changes over $10 \mathrm{yr}(\boldsymbol{\Phi})$, using the following equation (Weller, 1994):

$$
\mathbf{\Phi}=i \mathbf{b G} /\left(\mathbf{b}^{\prime} \mathbf{P b}\right)^{0.5}
$$

where $i$ is the selection intensity, $\mathbf{b}$ is the vector of breeding index coefficients, $\mathbf{G}$ is the genetic variance matrix, and $\mathbf{P}$ is the phenotypic variance matrix, computed as the sum of the genetic and residual variance matrices. The index coefficients for the Israeli breeding index are given in Table 3. The selection intensity was set to 3 , which roughly corresponds to the cumulative selection intensity over the 4 paths of selection obtained after $10 \mathrm{yr}$ in an advanced breeding program (Weller, 1994). The contribution of each $j$ trait to the total selection index $\left(c_{j}\right)$ was computed as

$$
c_{j}=\frac{\operatorname{abs}\left(b_{j} g_{j}\right)}{\sum_{j=1}^{J} \operatorname{abs}\left(b_{j} g_{j}\right)},
$$

where $b_{j}=$ the index coefficient for trait $j, g_{j}=$ the genetic standard deviation for trait $j$, and "abs" denotes absolute value. The $c_{j}$ values are also given in Table 3 .
In addition to the current selection index, which does not include the disease traits, expected genetic responses were computed for an alternative index, with negative index coefficients set so that ketosis, metritis, and retained placenta each accounted for $1 \%$ of the index and mastitis for $4.4 \%$ of the index. The contribution of mastitis to the index was set to equal $40 \%$ of the selection currently applied to SCS, following Govignon-Gion et al. (2012). The intensity applied to SCS was reduced accordingly so that the total fraction applied to both traits was equal to the contribution of SCS in the current index. The index coefficients for the proposed index and the corresponding $c_{j}$ values are also given in Table 3.

\section{RESULTS AND DISCUSSION}

Frequencies of incidence for ketosis and retained placenta and mean mastitis score by freshening year of first-parity cows are shown in Figure 1, and frequencies of incidence for metritis are shown in Figure 2. Incidence was highest for metritis and lowest for retained placenta. No clear phenotypic trends were evident for any of the diseases. Frequencies for ketosis and retained placenta were similar to most previous studies for Holsteins (Kelton et al., 1998; Parker Gaddis et al., 2012). Frequency for metritis was higher because the definition used was more inclusive than most previous studies, as described in the methods section. Frequency for mastitis was lower than most previous studies (e.g.,

Table 2. The number of animals included in the REML analyses

\begin{tabular}{llcc}
\hline \multirow{2}{*}{ Trait } & Parity & $\begin{array}{c}\text { Cows with } \\
\text { records }\end{array}$ & $\begin{array}{c}\text { Ancestors } \\
\text { without records }\end{array}$ \\
\hline All diseases & 1 & 229,571 & 152,591 \\
All diseases + index traits & 1 & 185,113 & 125,849 \\
Ketosis & 1 & 262,659 & 129,851 \\
& 2 & 194,431 & \\
Metritis & 3 & 132,024 & 128,149 \\
& 1 & 261,846 & \\
Retained placenta & 2 & 200,221 & 128,470 \\
& 3 & 142,106 & \\
Mastitis, all herds & 1 & 196,123 & \\
& 2 & 139,123 & \\
Mastitis-SCS, all herds & 3 & 261,698 & 126,697 \\
& 1 & 200,121 & \\
Mastitis, selected herds ${ }^{1}$ & 2 & 142,119 & 84,438 \\
& 3 & 198,704 & \\
Mastitis-SCS, selected herds ${ }^{1}$ & 1 & 157,285 & 84,438 \\
& 2 & 111,539 & \\
& 3 & 110,446 & \\
& 1 & 80,279 & \\
\end{tabular}

${ }^{1}$ First-parity herd-years with $\geq 50$ cows and $>4 \%$ mastitis. 
Table 3. Expected genetic trends after $10 \mathrm{yr}$ of selection with the current Israeli selection index and a proposed index including the disease traits

\begin{tabular}{|c|c|c|c|c|c|c|}
\hline Trait & \multicolumn{3}{|c|}{ Current index } & \multicolumn{3}{|c|}{ Proposed index ${ }^{1}$} \\
\hline Fat $(\mathrm{kg})$ & 41 & 0.23 & 8.48 & 37 & 0.22 & 8.48 \\
\hline Protein (kg) & 32 & 0.40 & 21.2 & 28 & 0.39 & 21.2 \\
\hline $\mathrm{SCS}^{3}$ & -0.13 & 0.11 & -300 & -0.09 & 0.07 & -180 \\
\hline Metritis $^{3}(\%)$ & -0.32 & 0 & 0 & -0.70 & 0.01 & -134 \\
\hline Mastitis $^{3}(\%)$ & 0.21 & 0 & 0 & 0.06 & 0.04 & $-3,015$ \\
\hline Retained placenta ${ }^{3}(\%)$ & 0.38 & 0 & 0 & 0.28 & 0.01 & -559 \\
\hline
\end{tabular}

${ }^{1}$ Ketosis, metritis, and retained placenta each comprise $1 \%$ of the index, the contribution of SCS to the index is reduced to $60 \%$ of its current value, and mastitis has a value that is $40 \%$ of SCS in the current index.

${ }^{2}$ Computed as index coefficient multiplied by the genetic standard deviation.

${ }^{3}$ Negative values are economically favorable.

Heringstad et al., 2005; Olde Riekerink et al., 2008; Pérez-Cabal et al., 2009), but within the range of studies summarized by Parker Gaddis et al. (2012). Most studies were based on relatively small samples of cows from selected herds and did not differentiate among parities. Heringstad et al. (2005) found a frequency of $15.8 \%$ in a sample of 372,227 first-parity Norwegian Red cows compared with $4 \%$ for Israeli Holsteins in the current study, but their analysis was also performed on a selected sample of the population.

In the fixed model analyses of the first-parity records, all fixed effects were significant $(P<0.001)$ for metritis and retained placenta. For ketosis, all effects were significant, except for gestation length. For mastitis, only the effects of herd-year-season and calving age were significant. First-parity dystocia increased the incidence of

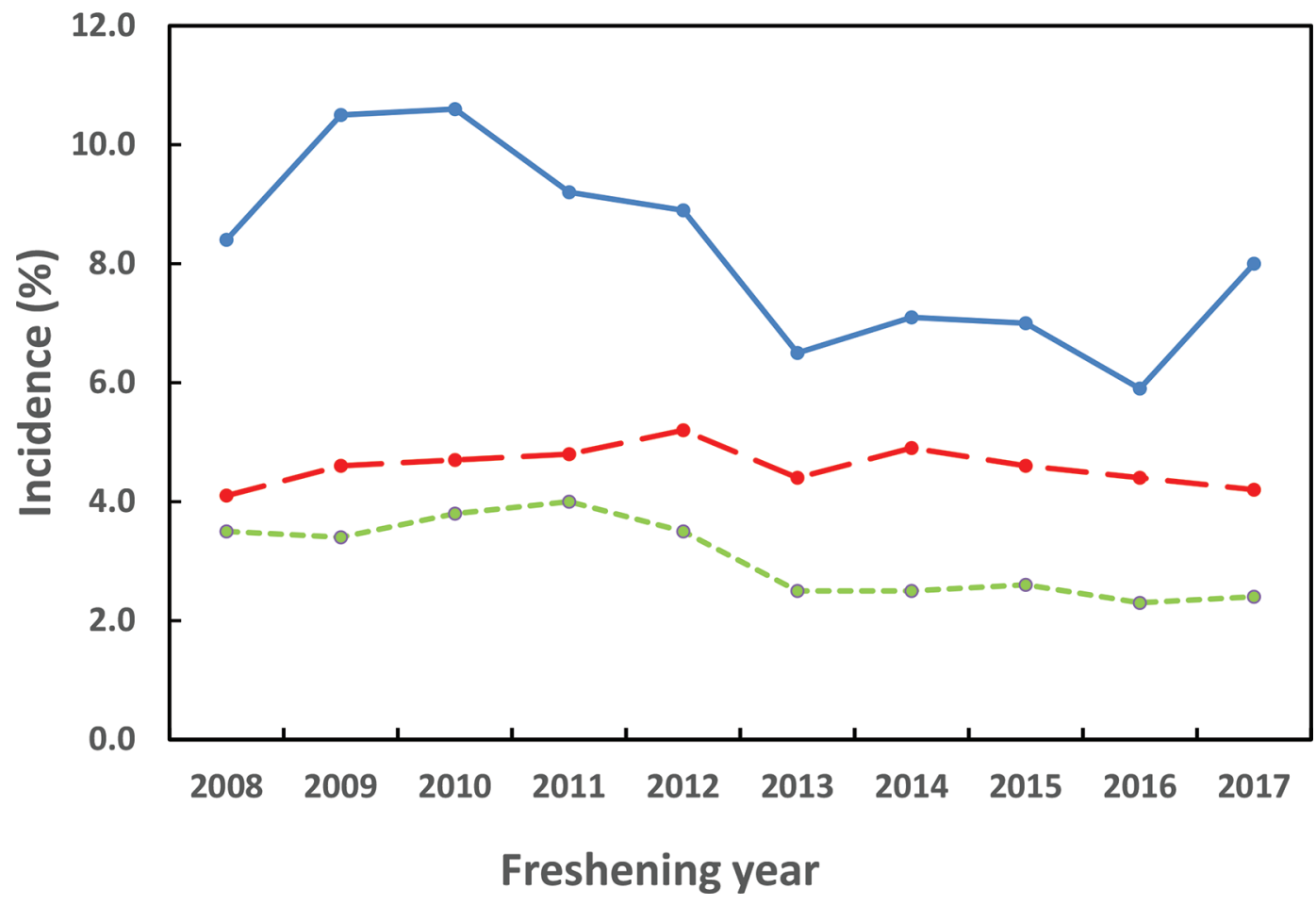

Figure 1. Frequencies of incidence for ketosis, mastitis, and retained placenta by freshening year of first-parity cows. Solid blue line, ketosis; red broken line, mastitis; green dotted line, retained placenta. 
Table 4. Heritabilites (on the diagonal) and genetic (above the diagonal) and residual (below the diagonal) correlations among the disease traits $(229,571 \text { first-parity cows })^{1}$

\begin{tabular}{lcccc}
\hline Trait & \multicolumn{1}{c}{ Ketosis } & Metritis & Mastitis & Retained placenta \\
\hline Ketosis & $0.049 \pm 0.004$ & $0.608 \pm 0.041$ & $0.150 \pm 0.115$ & $0.263 \pm 0.076$ \\
Metritis & $0.139 \pm 0.003$ & $0.068 \pm 0.005$ & $0.163 \pm 0.110$ & $0.549 \pm 0.060$ \\
Mastitis & $-0.003 \pm 0.002$ & $0.003 \pm 0.003$ & $0.004 \pm 0.001$ & $0.011 \pm 0.132$ \\
Retained placenta & $0.057 \pm 0.003$ & $0.128 \pm 0.003$ & $0.006 \pm 0.002$ & $0.014 \pm 0.002$ \\
\hline
\end{tabular}

${ }^{1}$ Standard errors are given after the estimates.

ketosis and retained placenta by $3.5 \%$ and metritis by $1.9 \%$, but it did not significantly affect mastitis rate.

Heritabilites and genetic and residual correlations among the 4 disease traits in primiparous cows are given in Table 4. Heritability was highest for metritis and lowest for mastitis, but all heritabilities were $<0.07$, similar to previous studies (Pryce et al., 2016). All the genetic correlations were stronger than the corresponding residual correlations. Genetic correlations between metritis on one hand and ketosis and retained placenta on the other were $>0.5$. Parker Gaddis et al. (2014) found a similar genetic correlation between metritis and retained placenta but did not find a significant genetic correlation between ketosis and metritis. Genetic correlations between mastitis and the other 3 diseases were not significantly different from zero, while Parker Gaddis et al. (2014) found a significant genetic correlation between mastitis and retained placenta of 0.33. As noted previously, Parker Gaddis et al. (2014) assumed equal heritabilities and genetic correlations of unity among parities for each trait.

Heritabilites and genetic and residual correlations for parities 1 to 3 for ketosis, metritis, and retained placenta are given in Table 5 . The first-parity heritabilities were similar to those in Table 4, and the heritabilities for the later parities were similar to the first-parity heritabilities for ketosis and metritis. All genetic correlations were $>0.7$, and all residual correlations were $<0.07$. As expected, genetic correlations were strongest between second and third parities, which were all $>0.9$, and lowest between first and third parities.

Heritabilites and genetic and residual correlations for parities 1 to 3 for mastitis for all herd-years and selected herd-years are given in Table 6 . Neither the heritabilities nor the genetic correlations were significantly different between the 2 analyses. Thus, the very low heritability does not seem to be due to inaccurate recording by the farmers. In both the whole and selected data sets, genetic correlations were all $>0.9$. It is hard to explain how genetic correlations of this magnitude could be obtained if recording was unreliable. In both data sets, heritabilities increased with increasing parity but were still $<0.07$ in third parity. For all 4 traits, first-parity heritabilities from the analyses including all 3 parities were not significantly different from the first-parity heritabilities in Table 4 that included all cows with valid first-parity records. The fact that heritabilities did increase significantly with increase in parity for retained placenta and mastitis may indicate that analyses of these traits by a single-trait animal model may not be appropriate.

Genetic and residual correlations between mastitis and SCS for all herd-years and selected herd-years are given in Table 7. The genetic correlations for the full and selected data sets were very similar for each parity and not significantly different. Both genetic and residual correlations increased with increase of parity, but all residual correlations were $<0.25$. Genetic correlations

Table 5. Heritabilites (on the diagonal) and genetic (above the diagonals) and residual (below the diagonals) correlations for parities 1 to 3 for ketosis, metritis, and retained placenta ${ }^{1}$

\begin{tabular}{llccc}
\hline Trait & Parity & 1 & 2 & 3 \\
\hline Ketosis & 1 & $0.051 \pm 0.003$ & $0.783 \pm 0.030$ & $0.713 \pm 0.037$ \\
& 2 & $0.036 \pm 0.003$ & $0.047 \pm 0.003$ & $0.912 \pm 0.025$ \\
& 3 & $0.020 \pm 0.004$ & $0.052 \pm 0.004$ & $0.057 \pm 0.004$ \\
Metritis & & & \\
& 1 & $0.078 \pm 0.004$ & $0.878 \pm 0.018$ & $0.804 \pm 0.027$ \\
& 2 & $0.046 \pm 0.003$ & $0.066 \pm 0.004$ & $0.963 \pm 0.011$ \\
Retained placenta & 3 & $0.031 \pm 0.004$ & $0.061 \pm 0.004$ & $0.066 \pm 0.004$ \\
& 1 & $0.015 \pm 0.001$ & $0.718 \pm 0.040$ & $0.850 \pm 0.035$ \\
& 2 & $0.013 \pm 0.003$ & $0.015 \pm 0.001$ & $0.984 \pm 0.030$ \\
& 3 & $0.008 \pm 0.003$ & $0.014 \pm 0.003$ & $0.031 \pm 0.001$ \\
\hline
\end{tabular}

${ }^{1}$ Standard errors are given after the estimates. The numbers of animals included in each parity for each analysis are given in Table 2 . 


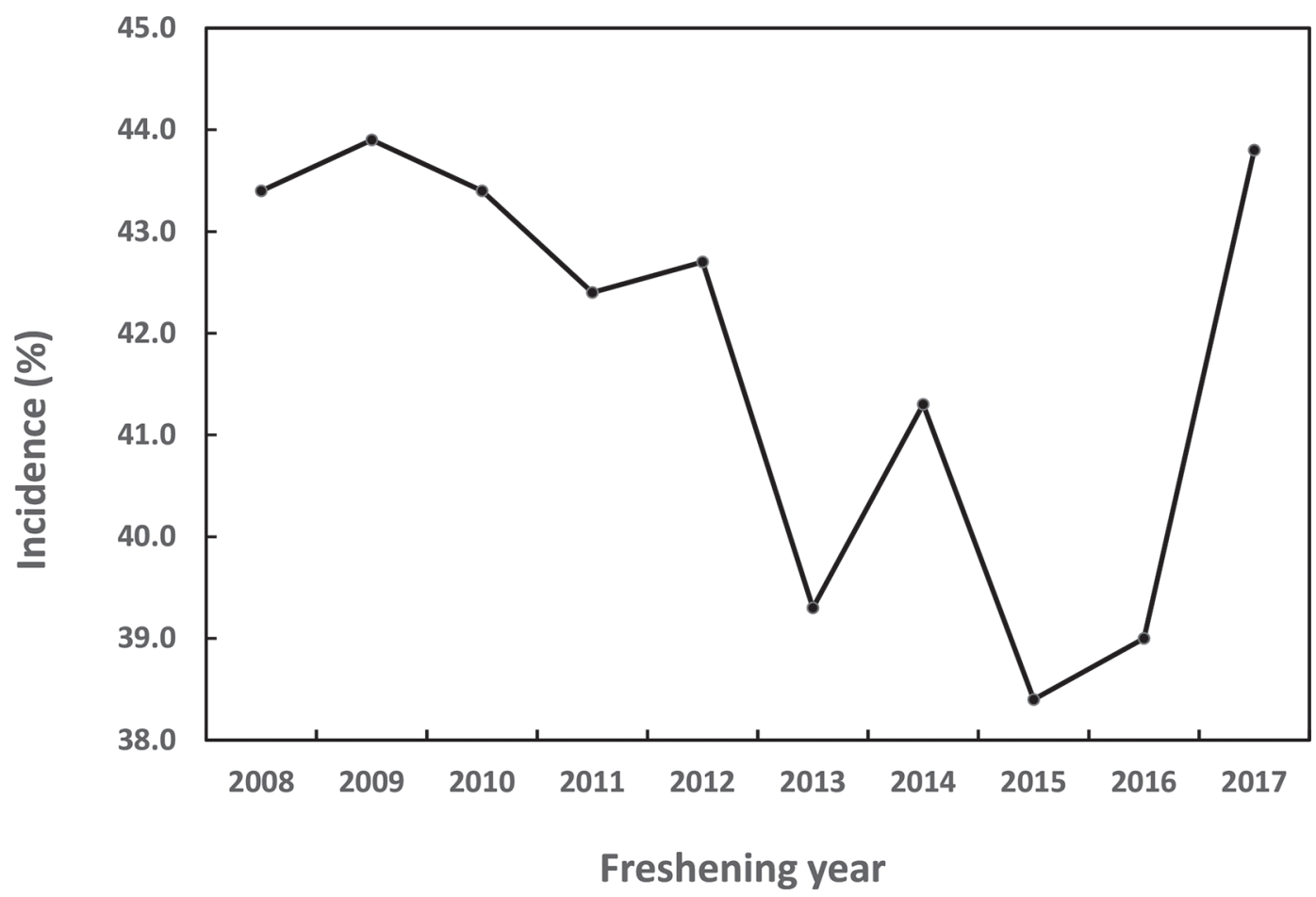

Figure 2. Frequency of incidence of metritis by freshening year of first-parity cows.

in third parity were $>0.8$. Heritability for first-parity SCS in the current study was $0.257 \pm 0.006$, similar to the results of Weller and Ezra (2004). Considering the first-parity genetic correlation between mastitis and SCS of 0.5, which increased in later parities, and the first-parity heritability of $\sim 0.25$ for SCS, as opposed to $\sim 1 \%$ for mastitis, SCS is clearly more useful as a selection objective.

Genetic correlations between the disease traits and the traits included in the Israeli selection index are given in Table 8. Genetic correlations between the disease traits and the milk production traits were all positive (economically unfavorable), while the genetic correlations between the disease traits and fertility and longevity were negative (economically favorable). Correlations between the disease traits and SCS were positive (economically favorable). The strongest correlations were obtained for mastitis. Correlations for mastitis with all the index traits were $>0.3$, except for fat yield. The correlation of 0.51 between SCS and mastitis is not significantly different from the value of 0.57 in Table 7 for first parity in the analysis of all herds.

The expected genetic changes after $10 \mathrm{yr}$ of selection with the current Israeli breeding index and the

Table 6. Heritabilites (on the diagonal) and genetic (above the diagonals) and residual (below the diagonals) correlations for parities 1 to 3 for mastitis for all herd-years and selected herd-years ${ }^{1}$

\begin{tabular}{|c|c|c|c|c|}
\hline \multirow[b]{2}{*}{ Herd-years } & \multirow[b]{2}{*}{ Parity } & \multicolumn{3}{|c|}{ Parity } \\
\hline & & 1 & 2 & 3 \\
\hline \multirow[t]{3}{*}{ All } & 1 & $0.013 \pm 0.002$ & $0.924 \pm 0.026$ & $0.925 \pm 0.026$ \\
\hline & 2 & $0.042 \pm 0.003$ & $0.041 \pm 0.003$ & $0.995 \pm 0.007$ \\
\hline & 3 & $0.042 \pm 0.003$ & $0.101 \pm 0.004$ & $0.055 \pm 0.004$ \\
\hline \multirow[t]{3}{*}{ Selected $^{2}$} & 1 & $0.016 \pm 0.002$ & $0.909 \pm 0.034$ & $0.901 \pm 0.035$ \\
\hline & 2 & $0.061 \pm 0.004$ & $0.045 \pm 0.004$ & $0.997 \pm 0.009$ \\
\hline & 3 & $0.042 \pm 0.004$ & $0.100 \pm 0.005$ & $0.062 \pm 0.006$ \\
\hline
\end{tabular}

${ }^{1}$ Standard errors are given after the estimates. The numbers of animals included in each parity for each analysis are given in Table 2 .

${ }^{2}$ Herd-years with $\geq 50$ records and $\geq 4 \%$ incidence of mastitis. 
Table 7. Genetic and residual correlations between mastitis and SCS for all herd-years and selected herdyears $^{1}$

\begin{tabular}{lccccc}
\hline & \multicolumn{2}{c}{ All herds } & & \multicolumn{2}{c}{ Selected herds } \\
\cline { 2 - 3 } \cline { 5 - 6 } Parity & Genetic & Residual & & Genetic & Residual \\
\hline 1 & $0.572 \pm 0.052$ & $0.115 \pm 0.003$ & & $0.536 \pm 0.051$ & $0.157 \pm 0.004$ \\
2 & $0.749 \pm 0.031$ & $0.155 \pm 0.004$ & & $0.759 \pm 0.027$ & $0.207 \pm 0.004$ \\
3 & $0.818 \pm 0.026$ & $0.164 \pm 0.005$ & & $0.830 \pm 0.023$ & $0.212 \pm 0.005$ \\
\hline
\end{tabular}

${ }^{1}$ Herd-years with $\geq 50$ records and $\geq 4 \%$ incidence of mastitis. Standard errors are given after the estimates. The numbers of animals included in each parity for each analysis are given in Table 2.

proposed index are given in Table 3. Changes with the current index were $<1 \%$ for metritis, mastitis, and retained placenta and $1.5 \%$ for ketosis. However, of the 4 diseases, ketosis has the lowest economic value. With inclusion of the 4 disease traits in the proposed index, metritis and ketosis would be reduced by $0.4 \%$ relative to the current index. Changes in mastitis and retained placenta were $<0.2 \%$. The proposed index would also decrease genetic gain for milk, fat, and protein production by $\sim 10 \%$ relative to the current index. Changes in the milk production traits were greater because these traits have much higher heritabilities. Changes in the other traits were not economically significant. It should be noted that these values are only approximate because the analysis is based only on first-parity records; in addition, persistency and calving traits, which are included in the breeding index, were not included in the analysis.

Although these disease traits clearly have economic value, the economic gain obtained by inclusion of these traits in the selection index is moot for the following reasons:

(1) heritabilities of all the disease traits are low;

(2) selection on SCS is more efficient than direct selection on mastitis;

(3) expected genetic changes for the disease traits over a horizon of $10 \mathrm{yr}$ using the current index are low;

(4) inclusion of these traits in the proposed index would result in only marginally improvements for the disease traits but adversely affect genetic gain for the production traits; and
(5) inclusion of these traits in the index would require computing genetic evaluations for the entire population for these traits 3 times annually, at a cost of at least 0.1 person-years of a master's-level technician, which is difficult to justify economically.

\section{CONCLUSIONS}

For ketosis, metritis, and retained placenta, firstparity dystocia increased the incidence of the disease. Heritability was highest for metritis and lowest for mastitis, but all heritabilities were $<0.07$, similar to previous studies. For all 4 diseases, genetic correlations among the first 3 parities were $>0.65$ and all residual correlations were $<0.07$. Selection of herd-years assumed to have more accurate recording of mastitis did not result in higher heritability estimates or genetic correlations with SCS. Genetic correlations between the disease traits and the 3 milk production traits were economically unfavorable, while correlations between the disease traits and the nonproduction traits included in the Israeli breeding index were economically favorable. Expected genetic changes in the disease traits after 10 yr of selection with the current index were all $<1 \%$, except for ketosis, which was predicted to increase by $1.5 \%$. With inclusion of the 4 disease traits in the proposed index, metritis and ketosis would be reduced by $0.4 \%$ relative to the current index. Changes in mastitis and retained placenta were $<0.2 \%$. The proposed index would also decrease genetic gain for milk, fat, and protein production by $\sim 10 \%$ relative to the current index. Inclusion of these traits in the breeding index is hard

Table 8. Genetic correlations between the disease traits and the traits included in the Israeli selection index $(185,113$ cows $)$

\begin{tabular}{lcccccc}
\hline Trait $^{1}$ & Milk & Fat & Protein & SCS & Fertility & Longevity \\
\hline Ketosis & 0.312 & 0.328 & 0.219 & 0.117 & -0.216 & -0.126 \\
Metritis & 0.126 & 0.117 & 0.094 & 0.155 & -0.248 & -0.220 \\
Mastitis & 0.400 & 0.141 & 0.397 & 0.510 & -0.388 & -0.374 \\
Retained placenta & 0.148 & 0.118 & 0.146 & 0.073 & -0.086 & -0.039 \\
\hline
\end{tabular}

${ }^{1}$ Negative values are economically favorable for the disease traits and SCS. 
to justify, based on the expected adverse effect on the production traits and the additional costs of computing evaluations every 4 mo.

\section{ACKNOWLEDGMENTS}

This research was supported by grant number 588042-5-063F from the US-Israel Binational Agricultural Research and Development (BARD) Fund, and by a grant from the Israel Dairy Board. We thank Ignacy Misztal and Shogo Tsuruta (Department of Animal and Dairy Science, University of Georgia, Athens) for use of the 2 REML programs and advice on implementation.

\section{REFERENCES}

Coffey, E. M., W. E. Vinson, and R. E. Pearson. 1986. Potential of somatic cell concentration in milk as a sire selection criterion to reduce mastitis in dairy cattle. J. Dairy Sci. 69:2163-2172.

Govignon-Gion, A., R. Dassonneville, G. Balloche, and V. Ducrocq. 2012. Genetic evaluation of mastitis in dairy cattle in France. Pages 121-126 in Interbull Bulletin No. 46. Proceedings of the 2012 Interbull Meeting, Cork, Ireland. https://journal.interbull.org/index .php/ib/article/view/1276.

Heringstad, B., Y. M. Chang, D. Gianola, and G. Klemetsdal. 2005. Genetic analysis of clinical mastitis, milk fever, ketosis, and retained placenta in three lactations of Norwegian red cows. J. Dairy Sci. 88:3273-3281.

Kelton, D. F., K. D. Lissemore, and R. E. Martin. 1998. Recommendations for recording and calculating the incidence of selected clinical diseases of dairy cattle. J. Dairy Sci. 81:2502-2509.

Liang, D., L. M. Arnold, C. J. Stowe, R. J. Harmon, and J. M. Bewley. 2017. Estimating US dairy clinical disease costs with a stochastic simulation model. J. Dairy Sci. 100:1472-1486.

Miglior, F., A. Fleming, F. Malchiodi, L. F. Brito, P. Martin, and C. F. Baes. 2017. A 100-year review: Identification and genetic selection of economically important traits in dairy cattle. J. Dairy Sci. 100:10251-10271.

Misztal, I. 1994. MTC-A multitrait REML program that uses the canonical transformation but allows for several random effects. http://nce.ads.uga.edu/ ignacy/oldprograms.html.
Misztal, I., S. Tsuruta, D. Lourenco, I. Aguilar, A. Legarra, and Z Vitezica. 2014. Manual for BLUPF90 Family of Programs. University of Georgia, Athens. http://nce.ads.uga.edu/wiki/lib/exe/fetch .php?media=blupf90_all2.pdf.

Olde Riekerink, R. G. M., H. W. Barkema, D. F. Kelton, and D. T. Scholl. 2008. Incidence rate of clinical mastitis on Canadian dairy farms. J. Dairy Sci. 91:1366-1377.

Parker Gaddis, K. L., J. B. Cole, J. S. Clay, and C. Maltecca. 2012. Incidence validation and relationship analysis of producer-recorded health event data from on-farm computer systems in the United States. J. Dairy Sci. 95:5422-5435.

Parker Gaddis, K. L., J. B. Cole, J. S. Clay, and C. Maltecca. 2014. Genomic selection for producer-recorded health event data in US dairy cattle. J. Dairy Sci. 97:3190-3199.

Parker Gaddis, K. L., M. E. Tooker, J. R. Wright, J. H. Megonigal Jr., J. S. Clay, and P. M. VanRaden. 2017. Development of genomic evaluations for direct measures of health in U.S. Holsteins and their correlations with fitness traits. 2017 Interbull Meeting, Tallinn, Estonia.

Pérez-Cabal, M. A., G. de los Campos, A. I. Vazquez, D. Gianola, G. J. M. Rosa, K. A. Weigel, and R. Alenda. 2009. Genetic evaluation of susceptibility to clinical mastitis in Spanish Holstein cows. J. Dairy Sci. 92:3472-3480.

Pryce, J. E., K. L. Parker Gaddis, A. Koeck, C. Bastin, M. Abdelsayed, N. Gengler, F. Miglior, B. Heringstad, C. Egger-Danner, K. F. Stock, A. J. Bradley, and J. B. Cole. 2016. Invited review: Opportunities for genetic improvement of metabolic diseases. J. Dairy Sci. 99:6855-6873.

SAS Institute Inc. 2011. SAS 9.1.3 Help and Documentation. SAS Institute Inc., Cary, NC.

Settar, P., and J. I. Weller. 1999. Genetic analysis of cow survival in the Israeli dairy cattle population. J. Dairy Sci. 82:2170-2177.

Shook, G. E. 1989. Selection for disease resistance. J. Dairy Sci. $72: 1349-1362$

Shook, G. E. 2006. Major advances in determining appropriate selection goals. J. Dairy Sci. 89:1349-1361.

Weller, J. I. 1994. Economic Aspects of Animal Breeding. Chapman \& Hall, London, UK.

Weller, J. I., and E. Ezra. 2004. Genetic analysis of the Israeli Holstein dairy cattle population for production and non-production traits with a multitrait animal model. J. Dairy Sci. 87:1519-1527.

Weller, J. I., A. Saran, and Y. Zeliger. 1992. Genetic and environmental relationships among somatic cell count, bacterial infection, and clinical mastitis. J. Dairy Sci. 75:2532-2540. 